\title{
DEVELOPMENT OF A BIOMARKER FOR LUNG INFLAMMATION IN COPD THROUGH ANALYSIS OF LABELLED LEUKOCYTE TRANSIT THROUGH THE LUNG CIRCULATION
}

Emma H. Baker, MRCP, PhD, Andrew Irwin, MSc, Amanda L. Brennan, MRCP, Brian Trost, BSc, Alan Britten, PhD, Sue Heenan, FRCR and Barry Peterson, PhD

WINNING ABSTRACT: Measurement of pulmonary leukocyte margination could be a useful biomarker of lung inflammation in COPD, but analysis is complicated by recirculation of labeled leukocytes.

15 minutes of planar nuclear images were obtained after injecting autologous ${ }^{99 m} \mathrm{Tc}$-labeled leukocytes in 4 never-smoked controls, 6 stable mild/moderate and 2 exacerbating COPD patients. COPD patients were also imaged for 10 minutes after in vivo red blood cell (RBC) labeling with ${ }^{99 \mathrm{~m}} \mathrm{Tc}$ and were re-imaged 2 weeks later to determine reproducibility. Activity as a function of time was measured in regions of interest over lungs and heart.

A multi-compartment mathematical model was used to correct for recirculation but failed to provide a biomarker that clearly separated controls from COPD. A simpler model for activity in lungs and heart as a function of time (A(t)) was applied only to time points before recirculation: $\left[A(t)=X_{1} \times\left(1-\exp \left(-X_{2} \times t\right)\right) \times \exp \left(-X_{3} \times t\right)\right.$, where $X_{i}$ are adjusted to match the data]. The ratio (R) of $X_{3}$ (downslope of curve) in the lungs to $X_{3}$ in the heart was investigated as a biomarker of margination. Values of $R$ were reasonable ( $1.06 \pm 0.08$ (SE)) for $\mathrm{RBC}$ (i.e. no margination) and $0.76 \pm 0.10$ for controls ( $\sim 25 \%$ margination). In stable COPD patients $R$ was significantly smaller $(0.19 \pm 0.09, p<0.01)$ than controls and was reproducible $(0.25 \pm 0.10)$. $R$ during exacerbation was surprisingly large $(0.88 \pm 0.22)$, possibly due to steroid treatment, but $R$ was similar to stable COPD patients 2 weeks later $(0.09 \pm 0.04)$.

R requires only 2-3 minutes of imaging and may be a useful biomarker of margination. However it remains to be shown whether $\mathbf{R}$ truly reflects inflammation in COPD.

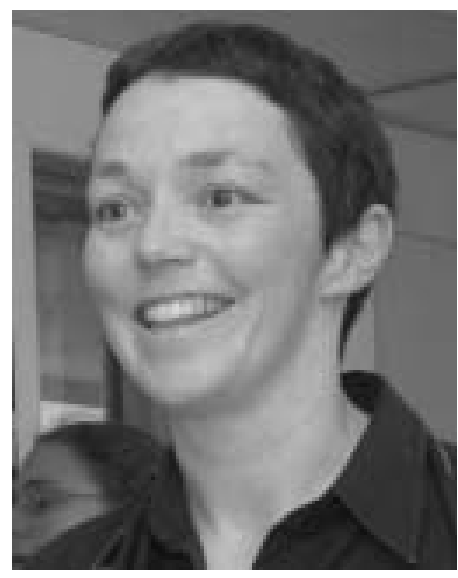

Emma H. Baker

St. George's, University of London, London, UK

\section{MY JOB AND THE UNIT IN WHICH I WORK}

I work in the Respiratory Unit of St. George's Hospital and St. George's, University of London (London, UK). St. George's Hospital is a large teaching hospital with $>1,000$ in-patient beds. The chest unit has grown considerably over the last $10 \mathrm{yrs}$ and now has seven medical consultants and one nurse consultant. The unit offers general respiratory in-patient and outpatient care and a wide range of subspeciality services, including airways disease, lung cancer, tuberculosis, pulmonary hypertension, interstitial lung disease, sleep medicine and interventional bronchoscopy. Respiratory research in the medical school is closely linked to clinical work and is focused around chronic obstructive pulmonary disease (COPD) and secondary pulmonary hypertension. Academic clinicians work side by side with basic scientists to ensure translational research for the benefit of patients. The department also provides teaching and training in respiratory medicine for medical and healthcare students and graduates. My role in the department is to provide clinical care for patients with COPD, to perform research and to organise and deliver undergraduate respiratory teaching.

\section{MY WINNING POSTER AS PART OF MY RESEARCH}

The primary focus of my research is the investigation of respiratory epithelial transport processes. Recent work is based on our novel finding that glucose is at low concentrations in lung liquid from healthy people, but this rises in patients with either lung disease or high blood glucose concentrations [1, 2]. We found that elevated glucose concentrations in the lung lumen were associated with development of hospital-acquired respiratory infection [3]. We have now validated a noninvasive method of measuring glucose concentrations in lung liquid collected as exhaled breath condensate and are determining whether breath glucose can be used as a marker of lung diseases, such as COPD.

The work described in the poster arose from collaboration with Dr Barry Peterson from the Clinical Technology Department at Pfizer (Groton, CT, USA). Although this work is separate from the main focus of my research, it fits with my interest in airway inflammation in COPD. St. George's Hospital has particular expertise in white cell scanning, as well as a large population of COPD patients, which made it an ideal location for the study.

\section{MY RESEARCH AS PART OF MY WORKING GROUP/ RESEARCH TEAM}

Respiratory research at St. George's Hospital is conducted by a multidisciplinary group, which is focused on improving the 
health of patients with COPD and other respiratory disease. A particular interest of the unit is the development and validation of pulmonary disease markers. My research thus fits well within the main themes of our unit. Prof. Paul Jones is internationally recognised for his work on the measurement of health status in patients with respiratory disease. He developed the St. George's Respiratory Health Questionnaire, which is used worldwide as an outcome measure in clinical and pharmaceutical research. Prof. Jones is currently leading a multinational study from St. George's Hospital to develop a standardised and reliable diary card to detect and quantify COPD exacerbations. Dr Rachel Garrod, Reader in Physiotherapy, has contributed to the evidence base underlying pulmonary rehabilitation in COPD. Other clinician researchers in the unit include Dr Brendan Madden, Consultant and Reader in Cardiothoracic Medicine, who is investigating the efficacy of new treatments in patients with secondary pulmonary hypertension, and Mrs Samantha Prigmore, Nurse Consultant, who has developed and commenced validation of self-management plans for COPD patients.

Clinical research in the unit is supported by basic science and I work closely with Dr Deborah Baines, Senior Lecturer in Basic Medical Sciences, who performs structural and functional studies of epithelial transport processes in immortalised and primary cultured respiratory epithelial cells. The gap between in vitro investigation and human studies is bridged by Prof. Walters in Child Health, who uses whole lung animal models to investigate mechanisms underlying the switch from fluidfilled lungs to air breathing at birth.

\section{THE IMPACT OF MY WORK ON CLINICAL OR RESEARCH PRACTICE}

Pulmonary biomarkers are required to increase understanding of mechanisms underlying pulmonary disease, as surrogate end-points for clinical trials and for clinical practice to assist in disease management. The measurement of pulmonary leukocyte margination (R) described in this poster clearly distinguishes between COPD patients and healthy volunteers

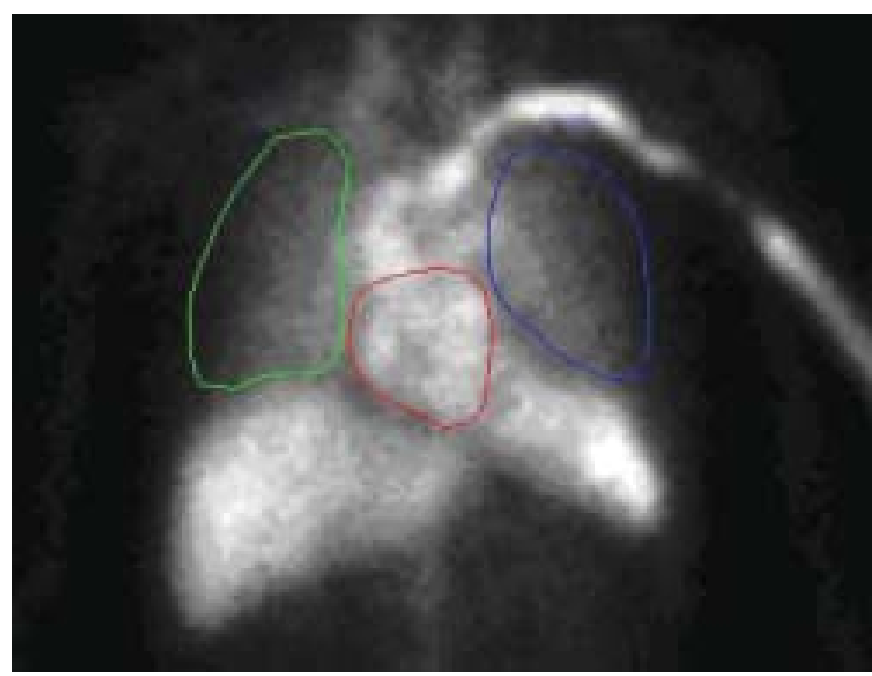

FIGURE 1. White cell scan of lung with defined regions of interest for right lung (green), left lung (blue) and heart (red)

and is altered by treatment known to reduce margination (steroids). $\mathrm{R}$ thus has potential as a surrogate end-point in trials of new treatments for COPD.

\section{REFERENCES}

1 Philips BJ, Meguer J-X, Redman J, Baker EH. Factors determining the appearance of glucose in upper and lower respiratory tract secretions. Intensive Care Med 2003; 29: 2204-2210.

2 Wood DM, Brennan AL, Philips BJ, Baker EH. Effect of hyperglycaemia on glucose concentration of airways secretions. Clin Sci 2004; 106: 527-533.

3 Philips BJ, Redman J, Brennan AL, et al. Glucose in bronchial aspirates increases the risk of respiratory MRSA in intubated patients. Thorax 2005; 60: 761-764. 